\title{
Physico-chemical and thermal properties of different biomass material selected for thermal gasification
}

H. Manjunath, Vijayakumar Palled, M. Veerangouda, Devanand Maski and C.T. Ramachandra

Received : 27.03.2018; Revised : 02.08.2018; Accepted : 18.08.2018

See end of the Paper for authors' affiliation

Correspondence to :

Vijayakumar Palled

Department of R.E.E.,

College of Agricultural

Engineering (UAS), Raichur

(Karnatak) India

Email : vs.palled@gmail.com
-ABSTRACT : Agricultural and forest biomass material were reported to be the potential feedstock for gasification by various researchers. The physical, chemical and thermal properties of biomass material play very important role in order to characterize the feedstock for energy conversion process. The physical properties (moisture content and bulk density), chemical properties (volatile matter content, ash content and total carbon content) and thermal properties (calorific value) of selected agricultural and forest biomass viz., pigeonpea stalk (Cajanus cajan), cotton stalk (Gossypium hirsutum) and vilaytee babool (Prosopis juliflora) for different length of sizes ranging from 25-50, 50-75 and 75-100 $\mathrm{mm}$ were determined using standard procedures. The moisture content of pigeonpea stalk, cotton stalk and vilaytee babool were found to be 3.28, 6.98 and 9.45 per cent, respectively. While the bulk density of these feed stock were reported to be 501, 465 and $556 \mathrm{~kg}$ $\mathrm{m}^{-3}$, respectively. The volatile matter content, ash content and total carbon content of pigeonpea stalk were $80.67,1.39$ and 17.94 per cent, respectively. While for cotton stalk these were 80.20, 1.43 and 18.37 per cent. Whereas, vilaytee babool these were $80.81,1.83$ and 17.36 per cent, respectively. The calorific value of $16.44,16.05$ and $17.49 \mathrm{MJ} \mathrm{kg}^{-1}$ was observed for pigeonpea, cotton stalk and vilaytee babool, respectively. The results obtained from the study indicated that the selected agricultural and forest biomass material were found to be potential for thermal gasification.

- KEY WORDS : Ash content, Biomass material, Bulk density, Calorific value,Total carbon content, Volatile matter content

- HOW TO CITE THIS PAPER : Manjunath, H., Palled, Vijayakumar, Veerangouda, M. Maski, Devanand and Ramachandra, C.T. (2018). Physico-chemical and thermal properties of different biomass material selected for thermal gasification. Internat. J. Agric. Engg., 11(2) : 276-281, DOI: 10.15740/HAS/IJAE/11.2/276-281. Copyright@2018: Hind Agri-Horticultural Society. 